\title{
Entrevista a Ricardo Musso
}

POR MATILDE MARTÍ, UNIVERSIDAD ORT URUGUAY

Conocido simplemente como Riki, tiene 51 años y durante casi 30 integró El Cuarteto de Nos, banda que fundó junto a su hermano Roberto y a su compañero de liceo Santiago Tavella. Hace unos siete años "se abrió", en busca de hacer música que no dependa de las letras. Hoy, con cinco reconocimientos en los Premios Graffiti por su disco ¡Formidable! (2014), que colgó gratis en internet y alcanzó unas 7000 descargas, se ríe de tener "más premios que público".

\section{¿Por qué hacés música?}

Porque me divierte. Desde chiquito me gustó el sonido y, como no tenía a quién grabar, empecé a hacer música para grabarme a mí mismo. Me gustó antes el sonido que la música, una cosa muy extraña.

\section{¿Qué fue lo primero que te llamó la atención?}

Un tocadiscos roto que había en la casa de mi abuela. Tenía tres años y no entendía qué era. Mi padre me dijo: "Eso se pone acá, si funcionara daría vueltas..., entonces yo probé lo que él me dijo y, aun sin andar, la aguja contra el disco hacía un sonido; empecé a imaginar que de adentro un disco de plástico salía un tipo hablando. Para mí fue mágico.

\section{Digamos que en la música encontraste la vía para hacer sonido.}

Nunca lo vi por separado. Hasta más grande, en los 60, no había visto a un tipo tocando música porfuera de un disco. Fueen el programadePipo Mancera, ahíhabía gente que cantaba y tocaba cosas que yo no sabía que eran instrumentos. En mi casa no había guitarra, no había nada; había un piano, pero no sabía bien qué era.

\section{¿Nadie tocaba?}

Tocaba mi madre cuando era chica. El piano estaba siempre cerrado. Yo no sabía que tenía teclas hasta que un día lo abrieron, pensaba que era una mesa. Entonces vi que había gente que tenía bandas, cantaban; había guitarras, baterías. Me gustó ese instrumento que no sabía qué era y empecé a armarme mis propias baterías con tachos y cosas. La jaula del canario era un excelente redoblante, por ejemplo arriba de una guía, porque el piso hacía de bordona. 
Componés, grabás y arreglás al mismo tiempo. ¿Cómo defines tu método de creación?

En mi caso, tengo todos los procesos mezclados porque soy muy caótico y no me puedo ordenar. Cuando trabajé en televisión hacía sketches grabados, los creaba, filmaba y editaba al mismo tiempo, no soy capaz de hacer un guión. Asígrabo mis discos: pongo RECygrabo, voy mezclando, componiendo y arreglando al mismo tiempo. ¿Acá hay letra? Entonces digo lalala. No tiene letra, bueno. No sé: REC, digo algo; esto me gustó, queda; esto no me gustó, lo borro. Vamos a pensar algo para acá, REC, no se me ocurre nada, vamos de vuelta.

\section{Entonces si hablamos del proceso creativo...}

No. No tengo un proceso creativo. Bah, tengo un proceso creativo que es así.

\section{Pero tampoco es improvisado lo que hacés.}

No, yo qué sé, hay gente que habla de la inspiración y de "quiero hacer una canción sobre tal cosa". A mí eso no me sale. De repente me pongo a hacer una letra y después la escucho de afuera y digo: "Ah, mirá, parece que estuviera hablando de tal cosa", entonces si le pongo esta frase acá va a quedar claro que sí, o mejor le pongo esta frase acá para que quede claro que no. No me importa lo que digan las letras, pero sí cuido que no digan cosas que no quiero decir.

\section{A veces que el público y la crítica entienden cosas que no estaban en las letras... \\ Más o menos sé para dónde va a agarrar la gente, lamentablemente siempre agarra para el mismolado. “Ah, ahí estás hablando de tal droga, ¿no?”. No, no me drogo, no me interesa. Entonces trato de evitar algunas palabras, sobre todo en Uruguay, donde el público está cada vez menos exigente y con menos paciencia como para tratar de entender una letra o imaginar una situación.}

\section{De todas formas, para vos la letra no vale por sí sola.}

No, es un ingrediente más. Junto con la música te genera determinado sentimiento o estado de ánimo en la escucha. Si se logra ese efecto, se hizo la magia. Me gusta que las frases, junto con la música, vayan creándote una imagen en el cerebro. Porque si no, no tiene ningún sentido hacer una canción.

Hay una canción en mi disco que se llama Sánchez, habla sobre un overloquista que tiene mucha experiencia, pero ahora es el supervisor de una textil, y es como un desperdicio. Da la imagen de eso, la letra no lo dice. De repente hay gente que me habla exactamente de eso, y eso es increíble.

Pero lo que más te interesa no son las canciones ni las melodías, sino los arreglos. ¿Creés que tu público percibe los arreglos?

No, el público no percibe nada. La mayoría del público no percibe nada de 
nada, percibe alguna palabra y la percibe mal. Pero con que haya diez que perciban las cosas que tienen que percibir al escuchar música... No te hablo de mi música, sino que escuchen un disco de los Beatles y no se queden en la melodía ni en la letra; hay cosas increíbles y mucho más importantes que las letras. Pero como es inglés, para nosotros es más fácil atender esas cosas; cuando hay una canción en español ya es más difícil que la gente separe. A mí me interesa que escuches una canción mía como si fuera en inglés. La letra no dice nada muy específico, para que no se cuelguen demasiado en la historia y puedan escuchar la música tranquilamente.

\section{Grabaste el disco en la cocina de tu casa. ¿Por qué?}

Porque tengo el baño cerca y la cocina muy cerca. En realidad no tengo otro lugar.

\section{Tenés un estudio.}

Tengo un estudio bastante grande pero ahora lo alquilé. Hay cosas que las podés grabar con monitores chicos, como secuenciar una batería, grabar un bajo con teclas, mismo grabar una guitarra por línea. Hay cosas que se pueden hacer en cualquier habitación, y fue la cocina porque era la única habitación donde mi mujer me dejaba tener mis cosas.

\section{¿Qué riesgo técnico tiene grabar en un ambiente así?}

Que a veces hay cosas que las grabás con auriculares pensando que están bien y cuando te vas a escuchar a los parlantes, están mal.

\section{Lo único que no grabaste vos fue la batería.}

En un principio eran baterías falsas, eran baterías mini o de sampler. Lamentablemente para mi ansiedad, porque ya tenía el disco terminado, vino Leonardo Baroncini de vacaciones y me dijo que me grababa las baterías. Cuando me mandó la primera ya me envenenó, porque es mucho mejor un ser humano tocando la batería; el golpe que tenía era maravilloso.

\section{¿Y cómo trabajaron? Porque él vive en Estados Unidos.}

Sí, lo grabó en el sótano de la casa con una tarjeta M Audio barata de ocho canales, y había que sacrificar micrófonos. Me mandaba todo por WeTranfer y yo le decía por Skype: "Bueno, bajá ese micrófono, subilo, a ver". Me mandaba el mp3, escuchaba: “Ta, dejalo así, no muevas más nada”.

\section{Cuando terminaste el disco decidiste subirlo a la web para descarga gratuita. \\ Me dije: "Lo voy a colgar, la gente lo va a bajar porque es gratis y, quieran o no, me conocen, para ver qué hizo éste que se fue del Cuarteto". Aparte, puse}


un botoncito de donaciones y me llegaron como 1.200 dólares, mucho más de lo que sacás por grabar cualquier disco. En algún momento pensé en ponerlo a un dólar, pero no, el uruguayo no tiene tarjeta de crédito, yo no tengo, más los menores, ya pedirle la tarjeta al padre para meterla en internet, pensar que te roban el número... En Uruguay no estamos acostumbrados, entonces más vale ponerlo en cero peso, que todo el mundo lo baje y llegue a todos.

\section{En dos días lo bajaron dos mil personas.}

Sí, y en total fueron siete mil descargas hasta el momento en que vinieron los sellos a decirme "te sacamos el disco". La verdad es que yo no tenía ningún interés en sacar el disco, no creía que me agregara nada.

\section{¿No sos un purista en ese sentido?}

No. Como los que dicen "ah, el vinilo". El vinilo sonaba horrible, no jodan. Montevideo Music Group me ofreció una buena plata para sacarlo, el adelanto de las regalías, cero riesgos.

Cuando recibiste el quinto Graffiti dijiste que tenías más premios que público.

Es verdad. Setenta personas tengo de público, más o menos.

\section{¿Y por qué tenés siete mil descargas y tenés setenta personas en vivo?}

Porque a la gente no le gusta mi música, yo qué sé. Le gusta salir a ver algo, hacer pogo, mover las banderas... No pasa por escuchar música, pasa por "uh, aguante", como una hinchada de fútbol.

\section{Recibiste cinco Premios Graffiti. ¿Cambió algo?}

Los premios son importantes. Para publicidad, por ejemplo, porque nadie sabía que yo había sacado un disco, sólo esos 70 que me van a ver. Recién ahora se empezó a vender el disco después de un año. Yo lo tenía gratis para bajar, ¿cómo no se enteraron? Claro, el público de la música acá es muy de escuchar lo quele ponen enfrente y no de buscar. Eso no me importa, pero al estar cantando me concentro mucho más en cantar que en tocar, y a mí lo que me divierte es tocar. Toco con auriculares grandes y no escucho a la banda, escucho el metrónomo, mi voz y mi guitarra.

\section{¿En vivo hacés eso?}

Sí. Tengo muy mala memoria y no me puedo aprender ninguna letra. En un momento tuve un telepromter pero tengo muy mala vista, además están las visuales, entonces no puedo tener una máquina con tres monitores, ya es demasiado. Además es muy feo estar rockeando y leyendo, es como el anti-rock. 


\section{¿Hace cuánto que sos docente?}

Nueve años. Acá en ORT aprendí Electrónica. Sé todo sobre las tripas delos aparatos, pero no vendían cuando empecé, entonces me los tenía que fabricar: compraba libros sobre circuitos y con eso armaba lo que veía que se usaba en las revistas de grabación.

Ala hora degrabar, ¿tenés en cuenta en qué dispositivo tevan a escuchar?

Cambiaron muchas cosas. Ya nadie escucha un disco entero, nadie tiene paciencia, me incluyo. Mientras estás escuchando un disco estás viendo otra cosa. Es muy difícil que alguien se siente a escuchar un disco entero; salvo que sea un tipo que ponga PLAY, se siente en un sillón, se sirva un whisky y se prenda un cigarro. No sé qué hace la gente cuando escucha música.

Otra cosa que ha cambiado es que la gente escucha en un celular o en el parlantito de la laptop. Entonces el bajo no sale, el bombo no sale, hay instrumentos que nunca van a salir, a no ser que se pongan auriculares. Ahora por suerte volvió la moda de los auriculares grandes: ahí se distingue cuándo se escucha bien y cuándo se escucha mal. Cuando yo hago una mezcla, la hago en los parlantes grandes; quiero que todo esté controlado por si alguien lo escucha bien. Son cuatro, pero no los dejo de lado porque son los buenos.

\section{¿Cómo sos vos como escucha?}

Me meto en Soundcloud o en Bandcamp, ordeno por fecha y aparece Prince al lado de un tipo que no grabó un disco en su vida. Dos por tres escucho cosas lindas. No soy de comprar o de escuchar discos. A veces me bajo el disco entero porque "ya que lo encontré, lo bajo y después lo escucho", pero nunca llega ese momento. Cuando voy a escuchar me gusta escucharlo con la tapa del disco quieta; no miro videos. Me gusta escuchar sin mirar. No me interesan ni los discos, ¿ dónde los guardo? Tengo un programa de radios y la gente me trae discos. No me traigan discos, pásenme un link. No tengo ni los discos de los Beatles, tengo un mp3 y ya está.

\section{Y cuando no había mp3, ¿tenías discos?}

Tenía muy pocos. Nunca tuve plata, le pedía discos prestados a Tavella, que tenía millones y yo los grababa en un casete de cromo.

\section{¿Cómo sos como usuario de redes sociales?}

Sólo tengo un Facebook del programa (Servo, Emisora del Sur).

¿Creés que haybandas o músicos que dentro de 20 años sevan a escuchar, así como permanecen Estómagos y Traidores?

Creo que sí, pero no porque lo que escuchaba era mejor que lo que hay ahora, sino porque la gente se recuerda a sí misma en esa época, siendo joven, en su mejor versión. 